\title{
Images of the respiratory system in ancient Egypt: Trachea, bronchi and pulmonary lobes
}

\author{
Jakub Kwiecinski MSc
}

J Kwiecinski. Images of the respiratory system in ancient Egypt: Trachea, bronchi and pulmonary lobes. Can Respir J 2012;19(5): e33-e34.

Examination of ancient Egyptians' depictions of the respiratory tract, dating back to the 30th century $\mathrm{BC}$, reveals their awareness of the pulmonary anatomy: reinforced with cartilaginous rings, the trachea is split into two main bronchi, which then enter the lungs (lungs being divided into pulmonary lobes).

Key Words: Anatomy; Ancient Egypt; History; Respiratory system
$\Lambda$ ncient Egyptians were the first to create an elaborate system of Amedicine (1). Some parts of their medical knowledge are relatively well explored, including a pharmacopoeia with many treatments identified and considered to be quite reasonable (1). Other parts, such as knowledge of anatomy, including respiratory anatomy, remain less well known.

The best known depiction of the respiratory tract in Egyptian art is a particular hieroglyph that depicts a windpipe with a pair of lungs attached (Figure 1A) (1-3). This glyph was used to write some unrelated words (eg, 'to unite'). However, its primary meaning remains what it depicts: the respiratory tract. In more elaborated versions, cartilaginous rings of the trachea are visible, as well as a few lines on the lungs (frequently placed symmetrically on both lungs). In original descriptions identifying the hieroglyph, it was suggested that these lines were fissures separating pulmonary lobes (3). However, recent interpretations have identified them as indentations on the lung surface caused by the ribs (1). These glyphs show no sign of bronchi. The main basis for medical historians' ideas about ancient Egyptian notion of bronchi has been limited to obscure passages in ancient medical texts. The Edwin Smith papyrus (case 34) offers a description of the dislocated clavicles:

Two canals are under it (the dislocation): one to the right and

(one) on the left of his throat (and) of his bosom; they lead to his

lungs (4).

It is possible that the two canals on the sides of the throat described in the text are the two main bronchi $(1,5)$. The Ebers papyrus (paragraph $854 \mathrm{~m}$ ), describes the system of vessels inside the human body: "There are four vessels to the lungs and to the spleen (6)". One could suppose that two of the four vessels connected to the lungs and spleen are the bronchi (the others could be the pulmonary veins and artery) $(1,5)$. However, due to the ambiguity of the texts and the vagueness of ancient Egyptian ideas about the circulatory system, these canals or vessels may, in fact, be blood vessels or any conduits inside the human chest $(1,5)$. Ancient Egyptian knowledge of the bronchi thus remains arguable.

I draw attention to some unconventional versions of the glyph depicting the respiratory tract that appear to have escaped the attention of medical historians, and may confirm not only that ancient Egyptians noticed the separation of lungs into lobes, but also prove that they were well aware of the existence of the bronchi.

The first glyph (Figure 1B) comes from a damaged inscription on a broken stone vessel from the reign of the first dynasty king Andjib

\section{Des images du système respiratoire en Égypte ancienne : la trachée, les bronches et les lobes pulmonaires}

L'examen des descriptions du tube digestif en Égypte ancienne, qui remontent au $30^{\mathrm{e}}$ siècle avant Jésus-Christ, révèle leur connaissance de l'anatomie pulmonaire : renforcée par des anneaux cartilagineux, la trachée se divise en deux bronches principales qui pénètrent dans les poumons (les poumons étant divisés en lobes pulmonaires).

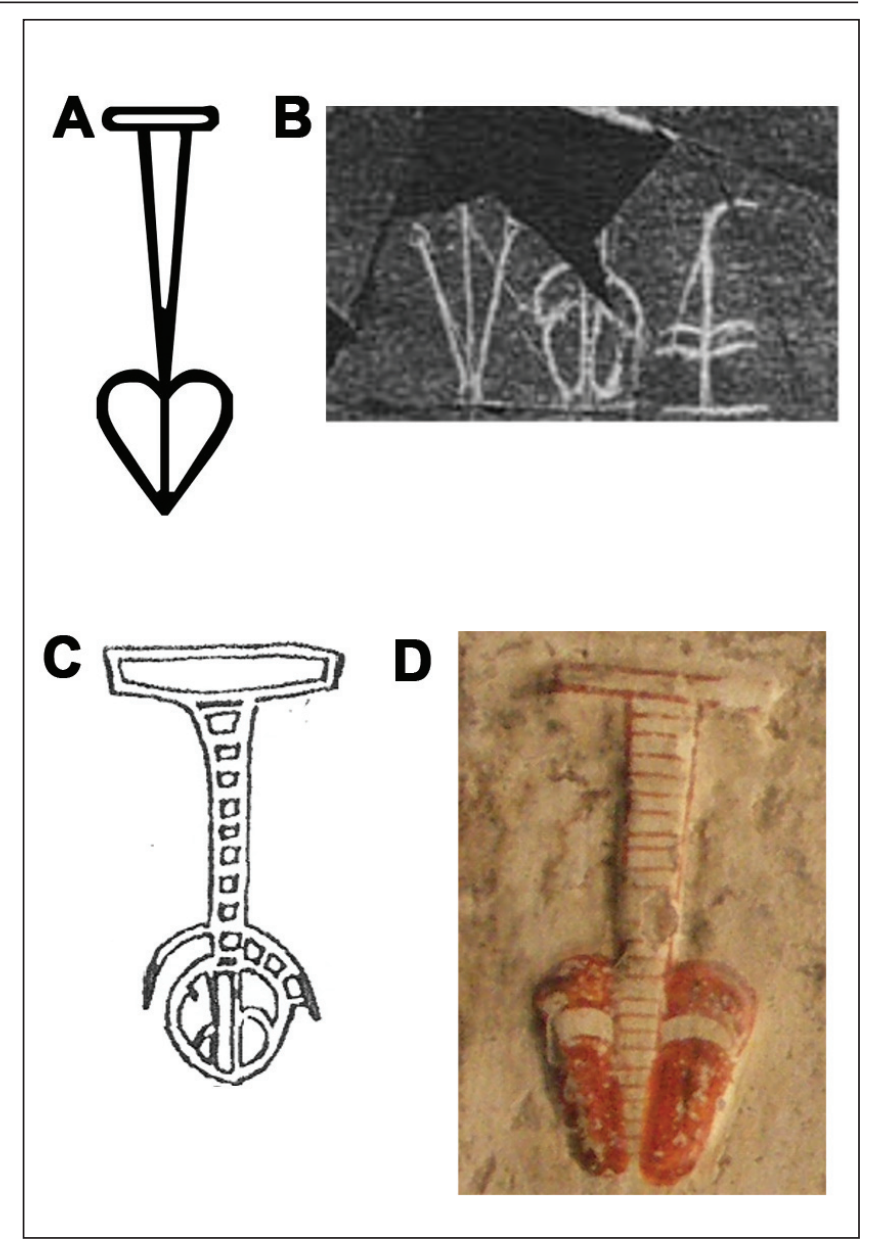

Figure 1) Various versions of the ancient Egyptian hieroglyph depicting the respiratory system. A Conventional depiction (from the Rosette-Mury ${ }^{(}$ hieroglyphic font set); B Depiction on a broken first dynasty vessel, surrounded by two other glyphs (photography reproduced from reference 9); C Depiction on a sixth dynasty vessel (drawing reproduced from reference 10); D Depiction from an 18th dynasty tomb (photography courtesy of Vincent Euverte)

Department of Rheumatology and Inflammation Research, Sahlgrenska Academy, University of Gothenburg, Gothenburg, Sweden, Correspondence: Mr Jakub Kwiecinski, Department of Rheumatology and Inflammation Research Sahlgrenska Academy, University of Gothenburg,

PO Box 480, Gothenburg 405-30, Sweden. Telephone 46-73-958-7926, e-mail jakub.kwiecinski@rheuma.gu.se, jkwiecinski@gmail.com 
(circa 30th century BC). Only traces of trachea remain, due to a crack in the vessel, but other inscriptions from the reign of this king show that it was most likely marked with cartilaginous rings. The lungs are obviously divided into separate pieces (7), which makes this inscription the earliest known depiction of pulmonary lobes (surprisingly, each lung has only two lobes, with similar lobe sizes on both left and right sides).

Another interesting depiction (Figure 1C) is found on a stone vessel marked with the name of king Teti from the sixth dynasty (circa 24th century BC). The style of the inscription is archaic, suggesting that it is either a reused early dynastic vessel (therefore, close in age to the aforementioned glyph) or a deliberate attempt to follow the archaic style (7). Pulmonary lobes are again present and now have different sizes on each side (once more, only two lobes on each side are depicted). More interestingly, a trachea covered by cartilaginous rings obviously is divided into two parts, most likely two main bronchi. For an unclear reason, one of them is shown surrounded by cartilaginous rings, unlike the other. The position of the presumed bronchi 'over' lungs, although anatomically incorrect, may be credited to a typical ancient Egyptian attempt to show all of the important components of the depicted object. This often results in the artist mixing different perspectives and angles of view, thus creating one composite, seemingly incorrect, image (8).

Bronchial-like structures can also be found in much later inscriptions (Figure 1D). This glyph comes from a tomb of the nobleman Pahery in El-Kab (18th dynasty, circa 15th century BC). Here, two bronchi on the sides of a trachea clearly stand out from red-coloured lungs (Figure 1D).

All three described glyphs significantly depart from its conventional, most common version, thus revealing the extent of the ancient Egyptian's knowledge of anatomy, proving their awareness of the bronchi and pulmonary lobes. They also allow a better interpretation of the lines found on the lung surface of the 'conventional' glyphs. It appears most likely that - depending on the artist's intention - these lines either symbolize fissures (especially when placed asymmetrically, similar to Figure 1C) or bronchi (especially when placed symmetrically, similar to Figure 1D).

In summary, ancient Egyptians were aware that the trachea, reinforced with cartilaginous rings, splits into two main bronchi, which in turn lead into the lungs divided into pulmonary lobes. An impressive knowledge for the dawn of medicine and civilization!

ACKNOWLEDGEMENTS: The author is grateful to Vincent Euverte from the 'Projet Rosette' for providing photography of Pahery's tomb and to Association Égyptologique Reine Elisabeth for permission to reproduce Figure 1C.

\section{REFERENCES}

1. Nunn JF. Ancient Egyptian medicine. Norman: University of Oklahoma Press, 1996.

2. Gardiner AH. Egyptian grammar: Being an introduction to the study of hieroglyphs. 3d edn. Oxford: Griffith Institute, Ashmolean Museum, 1957.

3. Borchardt L. Miscellen - "die Lunge”. Zeitschrift für Ägyptische Sprache und Altertumskunde 1905,42:80-81.

4. Breasted JH, New York HS: The Edwin Smith surgical papyrus. Chicago: The University of Chicago Press, 1930.

5. Ghalioungui P. The house of life; Per ankh. Magic and medical science in ancient Egypt. Amsterdam: BM Israël; 1973.

6. Ghalioungui P. The Ebers papyrus: A new English translation, commentaries and glossaries. Cairo: Academy of Scientific Research and Technology, 1987.

7. Lotus, papyrus, and the heraldic plants of ancient Egypt - A Visual Story <www.egyptology.nl/imag_txt/lotus_txt/lotus_0.html> (October 19, 2011).

8. Weeks KR. The anatomical knowledge of the ancient Egyptians and the representation of the human figure in Egyptian art. $\mathrm{PhD}$ thesis, Yale University, 1970.

9. Lauer JP, Lacau P. La pyramide à degrés. Le Caire,: Impr. de l'Institut français d'archéologie orientale; 1936-65.

10. Kaplony P. Steingefässe mit Inschriften der Frühzeit und des Alten Reichs. Bruxelles: Fondation égyptologique Reine Elisabeth; 1968. 


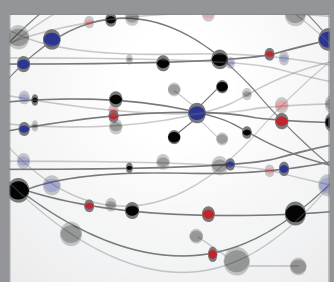

The Scientific World Journal
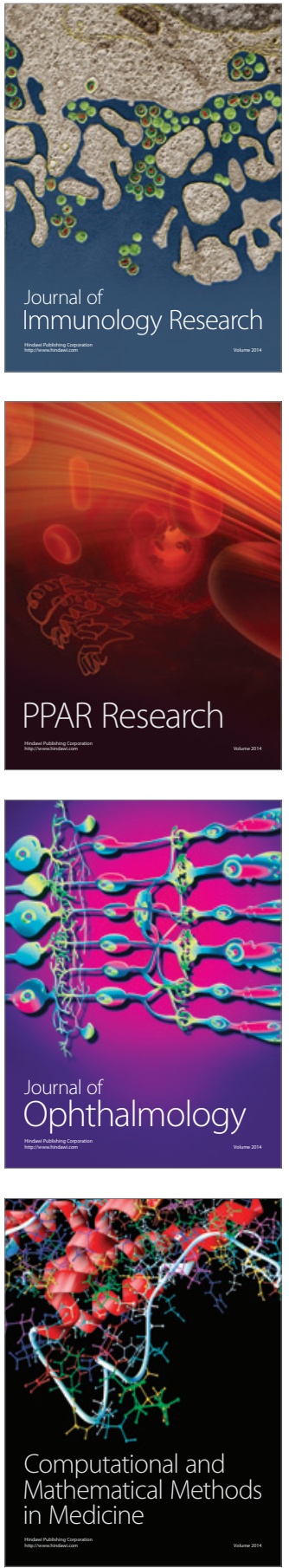

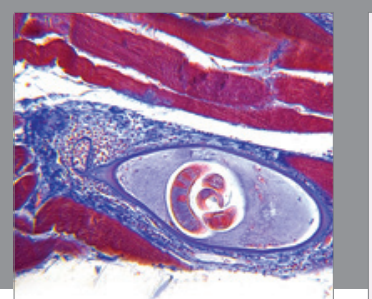

Gastroenterology Research and Practice

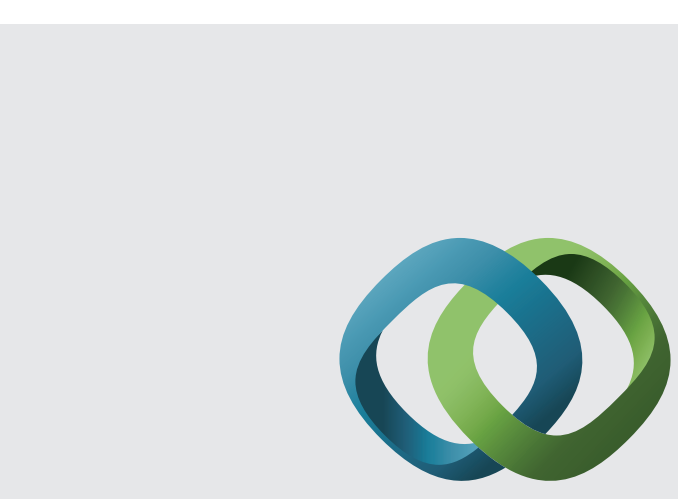

\section{Hindawi}

Submit your manuscripts at

http://www.hindawi.com
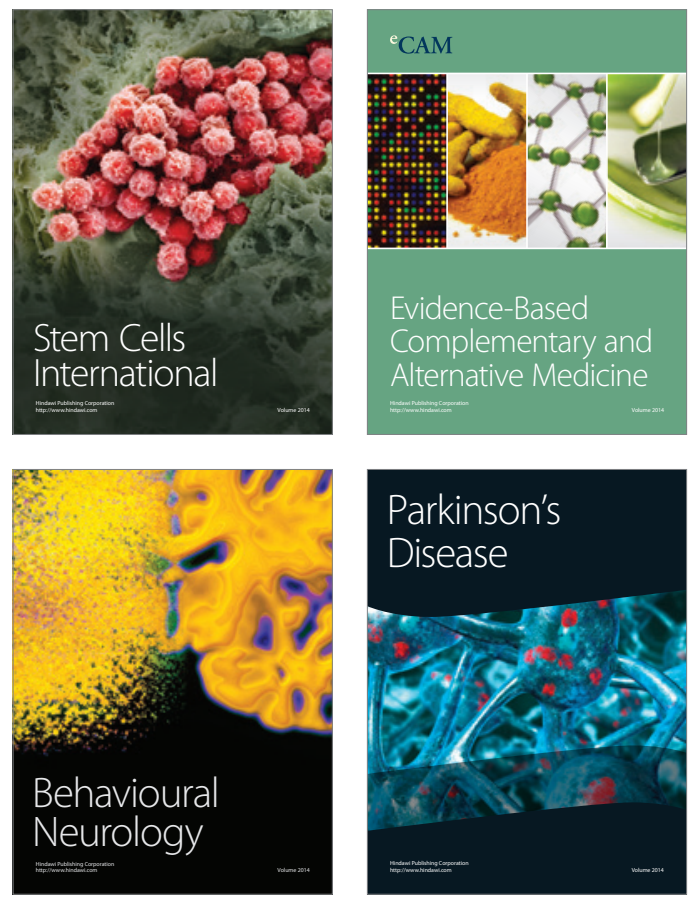
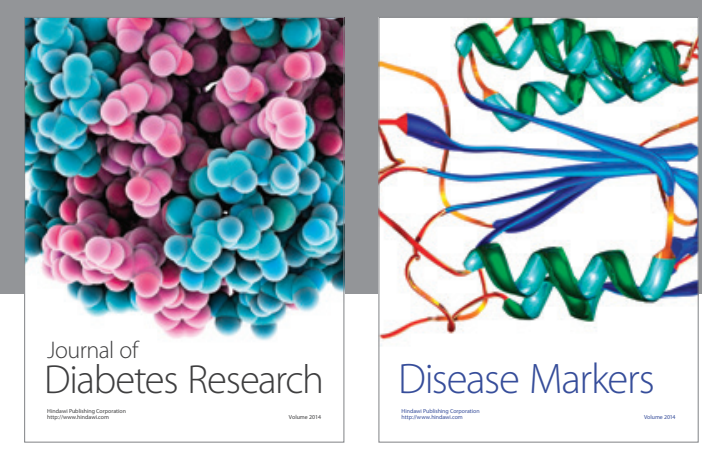

Disease Markers
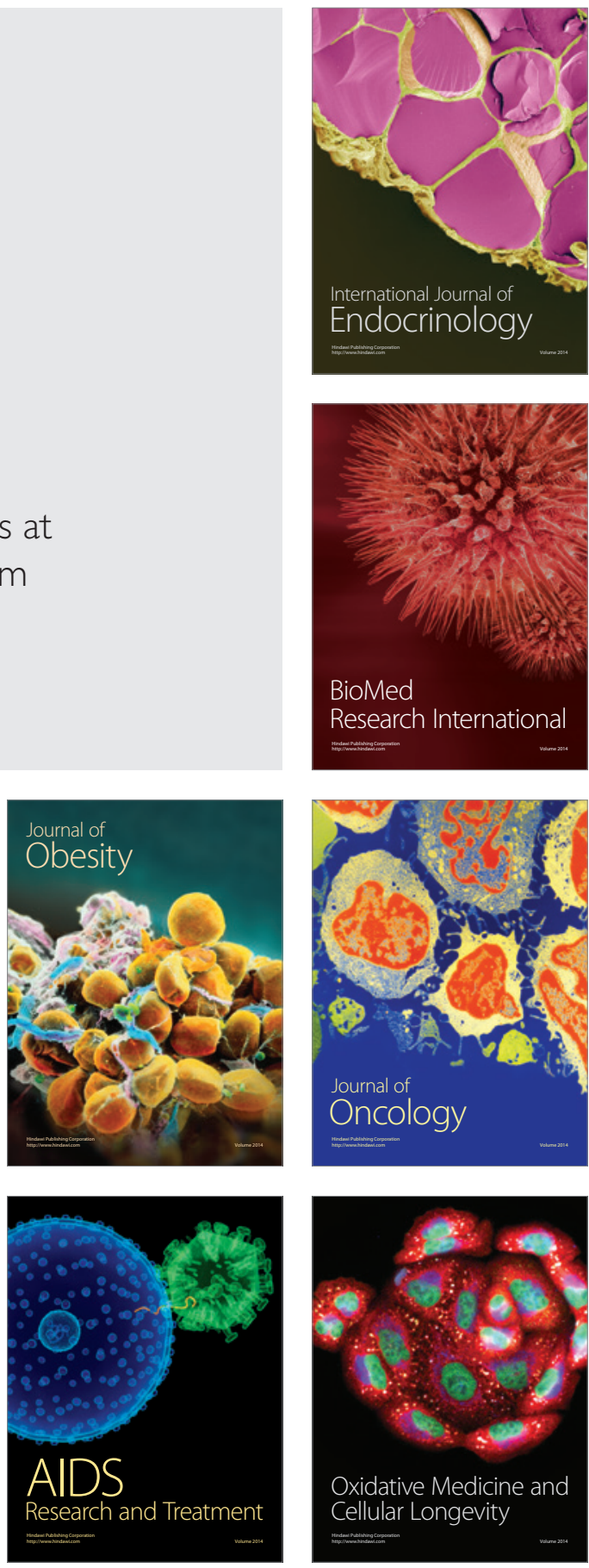